\title{
Imaging the Egyptian Obelisk at Kingston Lacy
}

\author{
Lindsay MacDonald \\ Faculty of Engineering \\ University College London \\ lindsay.macdonald@ucl.ac.uk \\ Ben Altshuler \\ Department of Classics \\ Oxford University \\ ben.altshuler@gmail.com
}

\author{
Jane Masséglia \\ Department of Classics \\ Oxford University \\ jane.masseglia@classics.ox.ac.uk \\ Sarah Norodom \\ Department of Classics \\ Oxford University \\ sarah.norodom@classics.ox.ac.uk \\ James Grasby \\ South-West Region \\ The National Trust \\ james.grasby@nationaltrust.org.uk
}

\author{
Charles Crowther \\ Department of Classics \\ Oxford University \\ charles.crowther@classics.ox.ac.uk
Andrew Cuffley
GOM UK Limited
Coventry
a.cuffley@gom.com

\begin{abstract}
The obelisk that stands in the grounds of the National Trust property at Kingston Lacy, Dorset, was brought from Egypt in $\mathbf{1 8 2 1}$ by William John Bankes. Known as the Philae obelisk, it has hieroglyphic inscriptions on the tapered granite column and Greek on the pedestal. In a multidisciplinary project to mark the success of the Philae comet mission, the inscriptions have been digitised by both reflectance transform imaging and 3D scanning. Novel imaging techniques have been developed to stitch together the separate RTI fields into a composite RTI for each face of the obelisk in registration with the geometric structure represented by the 3D point cloud. This will provide the basis for both paleographic examination of the inscriptions and visualisation of the monument as a whole.
\end{abstract}

Keywords: Digital archaeology, reflectance transform imaging, 3D scanning, palaeography, monument

\section{HISTORY OF THE OBELISK}

Kingston Lacy has one of the earliest collections of Egyptian artefacts in Britain, including the $6.7 \mathrm{~m}$ high granite obelisk on the south lawn. The collection was formed in the early 19th century by William John Bankes (1786-1855), heir to Kingston Lacy and its estates in Dorset and a noted traveller and antiquarian, connoisseur and art collector. Over two thousand years old, the obelisk once stood at the entrance of the temple of Isis on the island of Philae in the Nile in Upper Egypt. In 1815 Bankes discovered the fallen obelisk, half buried amidst the ruinous temple, and had it brought back to England.

Adventurous, unconventional and rich, William Bankes' eight year odyssey had started during the Napoleonic War, arriving in the war-torn Iberian peninsula in January 1813. By 1814 he had reached the great Egyptian city-port of Alexandria. "Of all the parts of the world which I have visited", he remarked, "Egypt and Nubia are those which interested me, beyond all comparison, the most, and have made the deepest impression upon my mind."

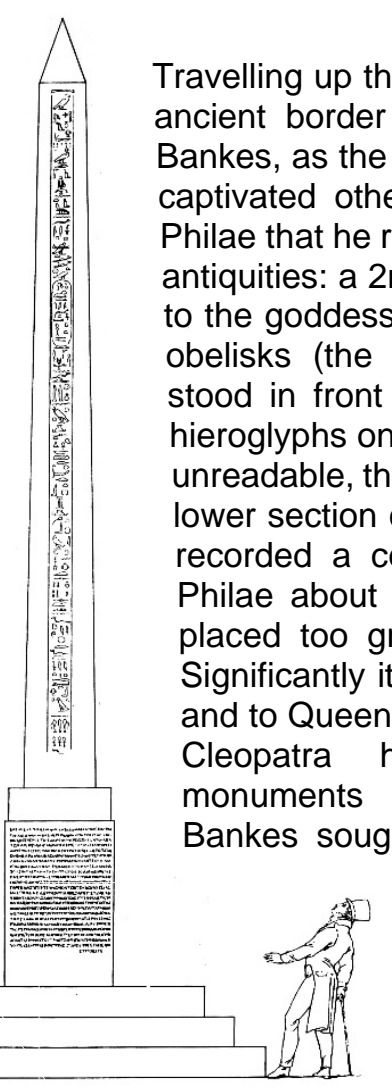

Figure 1: Elevation of the Philae Obelisk Lithograph by George Scharf (Nov 1821)
Travelling up the Nile, the island of Philae (on the ancient border of Egypt and Nubia) fascinated of the Temple of Isis. While the on the obelisk's four sides were then act that visiting officials $r$ and to Queen Cleopatra his sister and to Queen Cleopatra his wife.' Through recording monuments and their inscriptions in Egypt to understand the relationship between ancient Egyptian history and its architecture, and that of the Greeks. Then undeciphered, Egyptian hieroglyphics were the key, and the race to crack the enigma became intensely nationalistic. Bankes became 
caught up in it. Though the Greek text was in fact entirely different in meaning to the hieroglyphic inscriptions on the shaft of the obelisk above, Bankes rightly made a connection between the name Cleopatra in Greek and the incidence of a 'Cleopatra' cartouche in the sequence of hieroglyphs above. By correctly linking the names, he sparked an interpretive idea that was instrumental to Champollion's later decipherment.

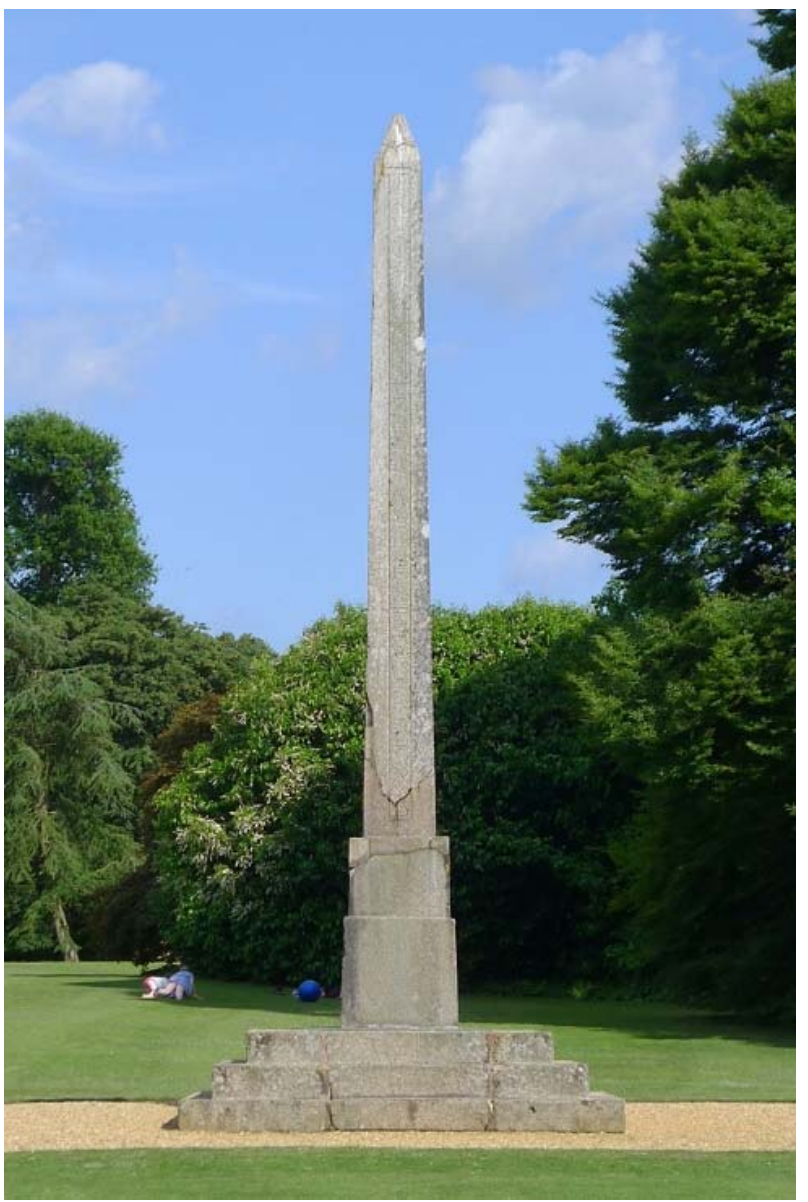

Figure 2: The pink granite obelisk as it stands today.

Bankes commissioned Giovanni Battista Belzoni (1778-1823) to devise a method of transport. Belzoni was a prolific Italian explorer and pioneer archaeologist of Egyptian antiquities, a resourceful and flamboyant character who stood $6 \mathrm{ft} 7$ in tall, and whose knowledge of engineering and experience as a circus strongman made him popular among collectors of antiquities looking to transport their acquisitions home. With the few materials that the island afforded him, he levered the six-ton obelisk towards a waiting boat on the Nile, only for the pier to collapse and for it to slide into the river. With great ingenuity he recovered the obelisk from the water, and loaded it on a boat for a hair-raising descent of the Nile to Alexandria. Loaded on a ship bound for London, it arrived in June 1821, and became the first Egyptian obelisk ever brought to Britain (Fig. 1). The Duke of Wellington assisted with the loan of a gun carriage to transport it to Kingston Lacy in Dorset.

\section{THE INSCRIPTIONS}

For the Oxford team, the Philae obelisk represents an exciting challenge, both as a monument and as an ancient text. For classics specialists at the Centre for the Study of Ancient Documents (CSAD), led by Professor Alan Bowman, working on the Corpus of Ptolemaic Inscriptions (CPI), the obelisk is an important record of Egyptian life under the Ptolemies in the 2 nd century $\mathrm{BC}$. The $\mathrm{CPI}$ project is creating a corpus of up-to-date editions of more than 550 Greek, bilingual and trilingual inscriptions on stone from Ptolemaic Egypt (323-30 BC), based on material collected and annotated by the late Peter Fraser FBA (1918-2007), who was the leading authority of the 20th century in the field of Hellenistic inscriptions in Egypt.

\subsection{The original site of the obelisk}

A visitor to the Nile island of Philae before 1972 may have been surprised to see the remains of this once great religious complex protruding from flood waters which reached half way up their walls (Fig. 3). The construction of the Aswan dams had created an artificial lake, which left the island inundated with the stones at risk or erosion from changing water levels (MacQuitty, 1976:8). The solution was a bold one: the Egyptian Antiquity Authority and UNESCO oversaw the block-by-block transportation and reconstruction of Philae's historic monuments on the nearby, and higher, island of Aigilkia (Edwards, 1980). By the time this great salvage operation was completed in 1980, one of the most famous monuments from Philae had already been in England for nearly 160 years (Fig. 2).

The obelisk was originally one of a pair which stood in front of the Great Pylon (gate) of the Temple of Isis which dominated the island's western edge. Less well-known is a small fragment of the second obelisk, which was acquired by Bankes in 1822 and eventually brought to Kingston Lacy in 1829 (MacQuitty, 1976: 137-41), and now lies in the grass behind its more famous companion.

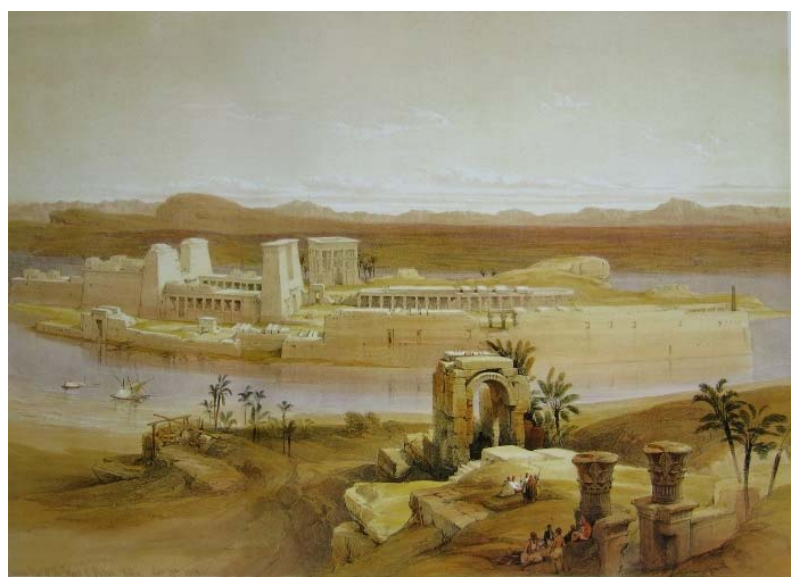

Figure 3: 'General View of the Island of Philae, Nubia' by David Roberts (1838) (Wikimedia Commons). 
The Temple of Isis, rebuilt by Ptolemy II (ruled 283$246 \mathrm{BC}$ ), was an imposing structure whose walls gathered reliefs and texts which celebrated the power of the gods and the rulers of Egypt. Similarly, the two obelisks were set up to be not only imposing structures, but also grand surfaces on which to record and publicise an important royal benefaction to the priests of Isis on Philae. Tired of absorbing the costs of the island's many visitors, the priests made an appeal for financial relief to their king, Ptolemy VIII (ruled c.170-116 BC), and his two wives, Cleopatra II (his biological sister) and Cleopatra III (his niece, daughter of Cleopatra II and their mutual brother, Ptolemy VI). On being granted a tax exemption, the priests celebrated their gratitude by inscribing a copy of their petition, together with the responses from Ptolemy and the two Cleopatras, in ancient Greek, the king's own language, on the base of the obelisk (Burstein, 1985:141-42 no.108) beneath an existing inscription in Egyptian hieroglyphs on the shaft (Wallis Budge, 1904: vol. 1, 148-159). The original impulse behind the use of two writing systems on a single monument may have been to stress the cultural hybridity of Egypt, and to harness the traditional 'weight' of hieroglyphs, but it is unlikely to have been a practical decision: by the second century $\mathrm{BC}$, hieroglyphs were already a highly specialised script, and unlikely to have been understood by many contemporary viewers (Vassilika, 1989:156). It was the Philae obelisk's dual scripts, however, that made it so important to nineteenth-century scholarship and to the eventual decipherment of hieroglyphs.

\subsection{Role of obelisk in deciphering hieroglyphs}

Egypt is unique among Hellenistic kingdoms in that inscriptions in its own language survive alongside the dominant Greek brought in by the Macedonian Ptolemies. The Rosetta Stone, discovered in the eponymous port in 1799, had three scripts: hieroglyphs, Demotic (a local Egyptian script, read right-to-left) and ancient Greek. At the time of its discovery, only one of these (ancient Greek), was understood. But painstaking work by scholars such as J.H. Åkerblad (1763-1819) and Baron A.I. Silvestre de Sacy (1758-1838), enabled the first steps in the decipherment of Demotic (Parkinson, 1999:31). And so, at the time of Bankes' travels in Egypt, hieroglyphs were the final obstacle to a complete reading of the Rosetta Stone.

Bankes' friend, the polymath Thomas Young, had already made an important observation in 1816 on the Rosetta hieroglyphs: that framed groups of symbols ('cartouches') were likely to represent royal names, and that one particularly frequent cartouche was a phonetic representation of the king's name 'Ptolemy' (MacQuitty, 1976:177). It was in this climate of scholarship that Bankes acquired the (first) Philae obelisk. He, Thomas Young and the British consul in Egypt, Henry Salt, believed that the obelisk's inscriptions were, like those of the Rosetta Stone, direct translations of one another, and that comparison between the Greek on the base and the hieroglyphs of the shaft would be decisive. In fact the two inscriptions of the Philae obelisk are not translations of one another. We know now that the shaft carries a traditional, honorific inscription for the royal family, while only the Greek contains the highly individual narrative of the priest's petition and the subsequent royal grant of tax-exemption. In 1821, however, with only Young's initial hypothesis about royal names to go on, two different approaches to hieroglyphs, and to the Philae obelisk were being undertaken simultaneously:

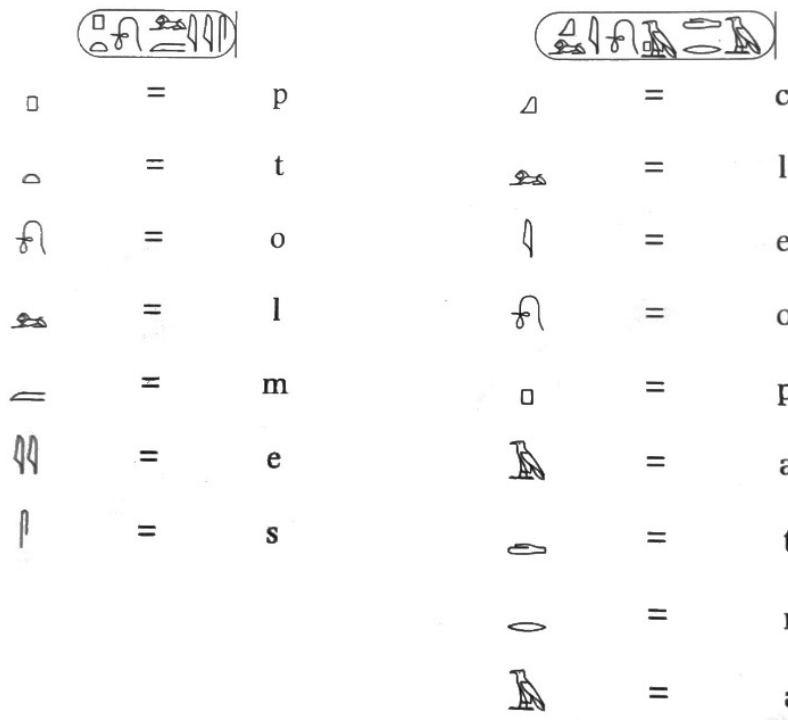

Figure 4: Champollion's phonetic reading of 'Ptolemy' and 'Cleopatra' cartouches (from Adkins, 2001:172).

In England, Bankes began to distribute copies of a lithograph of the obelisk and its inscriptions, which he had commissioned while it was being unloaded at Deptford (Adkins, 2001:170). Believing that the two texts were the same, he began by trying to identify the hieroglyphic parallels of the proper names which appeared in the Greek. The cartouche of 'Ptolemy' could be identified because of Young's work on the Rosetta Stone, and Bankes tentatively identified a second cartouche as 'Cleopatra', marking his suggestion in pencil in the margin of (at least some) of the lithographs he distributed. While the content of the inscriptions was not the same, the same royal names did appear in both. Bankes was wrong about the overall texts, but right about the 'Cleopatra' cartouche. Unfortunately, since both Young and Bankes subscribed to the traditional idea that hieroglyphs were largely logographs (one symbol for one word), they considered these phonetic name spellings to be the exception, something devised simply to cope with the ruler's foreign names, and their progress slowed.

In France, a young linguist named Jean-François Champollion was taking a different tack. He had been studying a papyrus written in both Demotic and 
Greek (the Papryrus Casati), and noticed certain similarities between the way 'Ptolemy' was written in Demotic, and the symbols which made up the 'Ptolemy' cartouche in hieroglyphs. Having identified the process by which hieroglyphs could be worked back to resemble Demotic, he reversed the process, and produced a hypothetical cartouche for a different royal name: 'Cleopatra' (Fig. 4). Only when he received a copy of Bankes' lithograph, from his friend Jean Letronne, was he able to test his hypothesis, and discovered that his hypothetical cartouche closely resembled one of those on the shaft of the Philae obelisk. He was now able to begin the process of deciphering the phonetic values of other hieroglyphs, and presented his famous Lettre à $M$. Dacier to the Académie des belles Lettres in Paris on Friday 27th September 1822.

The timing of Champollion's work on the 'Cleopatra' cartouche, at precisely the same moment that Bankes had proposed the same reading, caused some consternation among nineteenth-century scholars, not least Young who considered himself the originator of the phonetic decipherment, and Henry Salt who claimed Champollion was dishonest in not acknowledging Bankes' marginalia on the lithograph as his source (Salt, 1825:7). Modern scholarship still tends to be divided, often along nationalist lines, as to who began the process of decipherment. But hieroglyphs were not unlocked in a single step, nor from a single object. In the narratives, and indeed mythology, which has sprung up around the decipherment of hieroglyphs, the Rosetta Stone has taken a lead role, but the Philae obelisk is an important member of the cast.

\section{IMAGING THE OBELISK}

The obelisk is topical because on 12 November 2014, the landing module Philae, from the European Space Agency's robotic spacecraft Rosetta, successfully touched down on the comet 67P/ Churyumov-Gerasimenko. This lander was named in honour of the obelisk at Kingston Lacy. In anticipation of the comet landing, imaging specialists from CSAD, UCL and GOM UK Ltd set up their equipment in early October 2014 on a scaffold platform specially constructed by the National Trust. The objective was to acquire images of surface details on all four faces of the monument and to construct a complete 3D rendering.

\subsection{Camera setup}

In order to create an effective and comprehensive image set of the entire obelisk, each of the four façades was photographed in a series of overlapping vertical sections. As the obelisk is 6.7 metres in height, an elaborate scaffolding structure was erected around the obelisk with horizontal platforms at four levels.
A Canon 5D Mark III camera was fitted with a $50 \mathrm{~mm}$ macro lens, a Speedlight 600x flash and remote trigger. RTI-specific equipment included two twoinch reflective spheres, a metre of string, an Xrite colour target, and a Macbook Pro computer. The camera was mounted with the optical axis perpendicular to the face of the obelisk, at a distance of $70 \mathrm{~cm}$. The field of view spanned the width of the obelisk, as well as allowing space at the side for a pair of two-inch glossy black spheres, representing a total width of $c .1100 \mathrm{~mm}$. The image size of $5760 \times 3840$ pixels meant that the spatial resolution on the surface of the obelisk was approximately 5 pixels/mm (i.e. 200 micron/pixel). Each stage of the scaffold platform was divided into three or four sublevels. Each image set was assigned a façade orientation (north, south, east, west), a scaffold platform level $(A, B, C, D)$, and a sublevel $(1,2,3,4)$. For example, the lowest image set on the north façade was labelled North A1. The image set captured at each camera position contained from 24 to 80 images.

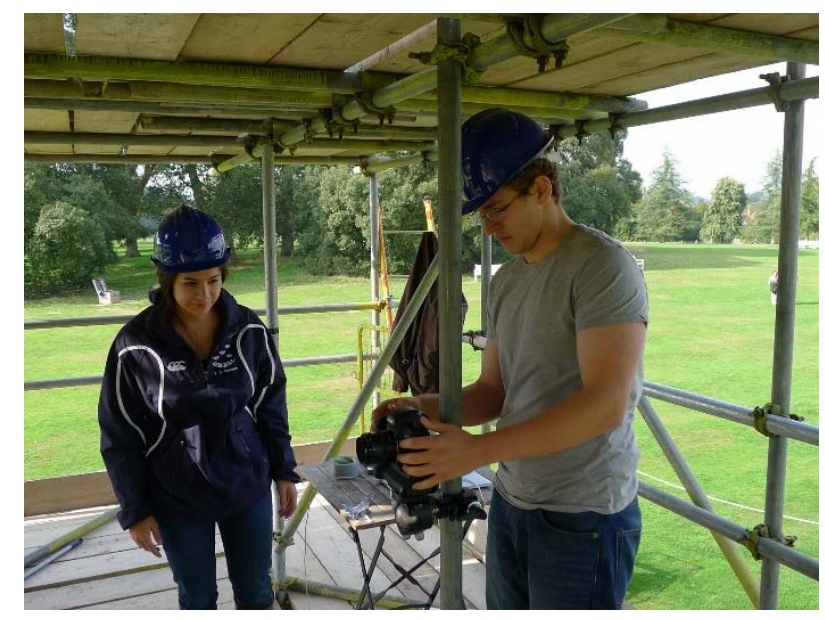

Figure 5: Photographic team at work, with the Canon camera clamped onto a scaffolding pole.

Because of space restrictions on the scaffolding, and in order to hold the camera as rigidly as possible during the capture sequence, a tripod was not used. Instead the camera body was clamped directly to the scaffolding. The reflective spheres were attached to lighting rods, also clamped to the scaffolding. The spheres were positioned to the side of the obelisk, so that from a side view one third of each sphere was visible. This arrangement was moved up the scaffolding successively to capture each of the sublevels. The flash was mounted onto a monopod to facilitate illumination of the obelisk from a wide range of angles. A metre of string was fastened to the flash and the other end touched before each exposure onto the obelisk surface at the centre of the image field, to maintain the light source at a constant distance throughout the entire capture sequence. The camera sensitivity was kept constant at ISO125 and the lens aperture at f/11. 


\subsection{Ambient light control}

The RTI assembly process assumes that each image is illuminated from a single known direction. It is therefore important to minimise any ambient light during the photography, and, as this project was conducted outdoors, it was a significant challenge for the photography team. Most of the imaging was done at night when ambient light was significantly reduced. Due to time constraints and weather conditions, however, some image acquisition had to be done during the day. To minimise the effects of sunlight, dark tarpaulins were fastened around the sides of the scaffolding to block out direct light. The shutter speed was adjusted depending on the amount of ambient light present, although never less than $1 / 250$ second, to allow sufficient shutter duration for the flash. The flash power was also adjusted to compensate for the intensity of ambient light, ranging from 1/1 (full) power to $1 / 64$ power. The camera was focused to include both the spheres and the face of the obelisk within the depth of field. During the capture sequence, the lens and camera were kept in manual mode to ensure that all settings remained constant.

\subsection{Reflectance Transform Imaging (RTI)}

The RTI technique was chosen for this project because, by use of multiple images with directional lighting, it produces a richer representation of the object than a single image. This makes it particularly suitable for capture of surface relief on monuments and archaeological sites (Earl et al, 2010). The builder software (freely available from Cultural Heritage Imaging) was applied in two stages. First the reflective highlight on the billiard ball in each image was analysed to determine the direction of the incident flash illumination. Then the intensity distribution at each pixel over the full set of images was fitted by hemispherical harmonics as basis functions. The resulting RTI file can be interpreted by the viewer software to show an interactive visualisation of the surface, as if a virtual light source were playing over a relief surface (Fig. 6).

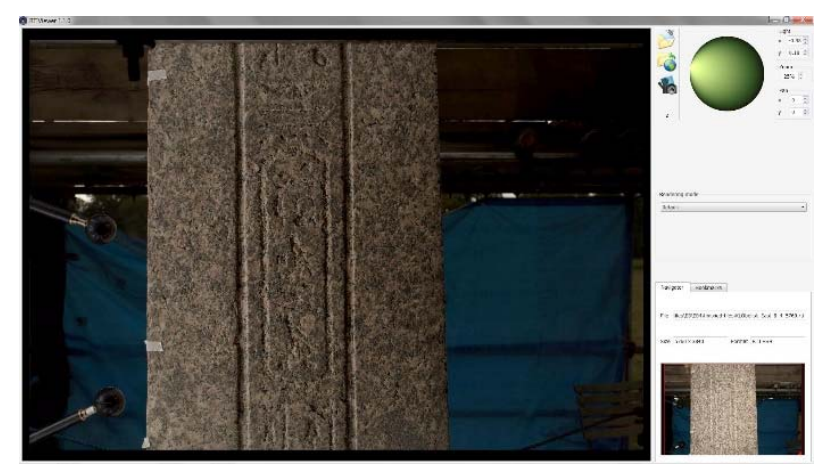

Figure 6: Screen shot of RTI viewer, showing the obelisk's cartouche of 'Cleopatra' on image set EB4.

\section{3D SCANNING THE OBELISK}

In addition to the photographic survey, the entire obelisk was scanned by a GOM 3D scanner and a complete point cloud produced. The scanner is designed for industrial sectors such as design, construction, manufacturing and quality assurance, that need coordinate measurement technology to digitise surfaces in order to compare real component parts with their reference data. The ATOS (Advanced Topometric Optical Sensor) system is able quickly and easily to digitise objects with a high local resolution and accuracy. It works according to the triangulation principle, meaning that the distance of each point is captured in a quasi-triangular measurement. The scanner projects a fringe pattern of light onto the object which is captured by both cameras. In order to digitise an object completely, multiple scans are required from different directions. To enable stitching of the multiple views accurately into a common coordinate system, reference markers are placed at random on or around the object. As these are viewed by the scanner, the associated data is positioned in 3D space to match the previously known location of that pattern.

For scanning the obelisk the ATOS Compact Scan $5 \mathrm{M}$ was used, with a pair of 5 mega pixel cameras, and a high power projector, giving a measurement volume of $500 \mathrm{~mm}$. The volume was chosen in order to provide the right balance between acquired resolution and ease of use. With the 'interesting area' of the inscriptions needing to be kept free from reference markers, it was important to ensure that they could be placed only on the smooth sides. During an initial site visit it seemed clear that the depth and distinctive markings of the hieroglyphs could be resolved using this method.

The approach for 3D capture was to wait until the RTI photography was complete, so that there were no issues with placing reference markers and to have sole use of the scaffold platform. The intended method was initially to perform a photogrammetry session for each of the scaffold stages and then stitch the results together into a common coordinate system of coded reference markers onto which the ATOS scanner could map the surface detail, giving local accuracy over a global scale.

This exercise would ideally have employed two people, but due to the time restraints, including the timetable for scaffold removal, it became a one-man operation. This posed a series of logistical challenges. The grounds of a stately home do not lend themselves well to the handling of sensitive metrology equipment. As it was late September before the project could be started we were subject to the vagaries of the autumn weather. Finally in early October a period of reasonable weather was forecast and a visit scheduled. 
The pre-site visit had been made several months before and it was not until seeing the obelisk with the scaffolding in place that it became clear that the premeasurement photogrammetry was not going to be possible without seriously affecting the project timescale. The decision was therefore made to use the ATOS scanner only, so the system would acquire the markers as it progressed, and so larger areas of overlap were made to ensure that all points were recognised. This is a legitimate approach to measurement with a small compromise on volumetric accuracy. It required more scans to be taken, but where each scan took only a few seconds this was acceptable.

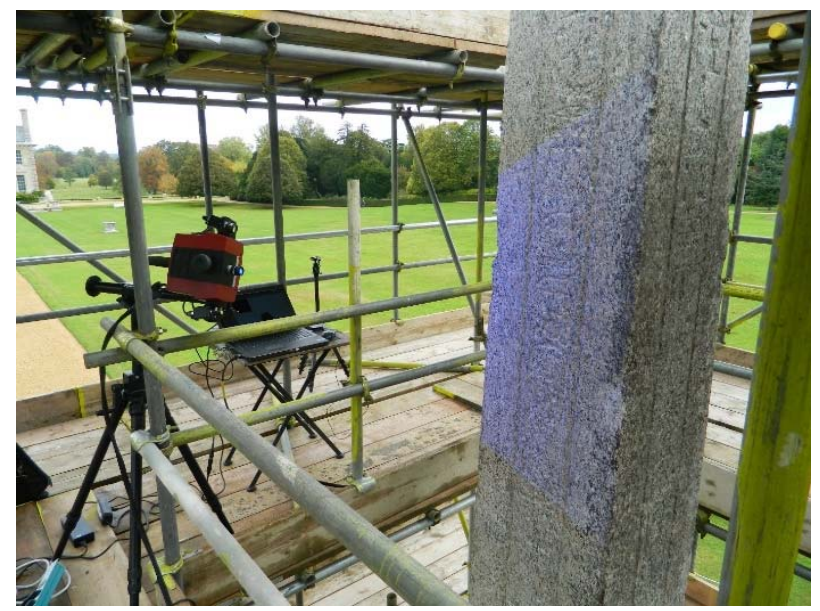

Figure 7: ATOS 3D scanner on the scaffolding platform.

It is worth noting that due to the nature of the granite surface and the form of the hieroglyphs, multiple angles of scan were often required to capture the vertical edges of the incisions. When using the overlap method of building up the complete scan it is possible that slight mismatches could accumulate over the complete object, giving a distorted shape. Since the obelisk has a wrap-around form, however, this type of misalignment did not occur.

Having determined the scanning method, the scanner, laptop and stand were manhandled up to the higher reaches of the obelisk with a view to working downwards. It was a bright day, and so even with the powerful projector available it was not possible to compete with the sun on the steeplyraked flats of the apex, yet there was a need to complete the higher levels whilst the weather was clement. A period of around 30 minutes was needed to hand position the reference markers for the complete object.

The scaffold structure was not consistent and it was often quite a stretch over to apply them to the surface. Calibration of the sensor was required, after the scanner had been bundled up the successive ladder stages. The set-up is shown in Fig. 7, with the ATOS scanner casting its blue light across the rose granite shaft of the obelisk, and the marker points just visible. Alongside the scanner is the processing laptop, and In the background on the left a corner of the house. Each level of the scaffolding needed a number of different views to get the required overlap and also the transition areas between levels. To achieve the most reliable and stable stitching, not only points but also large swathes of data were used for alignment of the 3D point clouds.

Later in the afternoon rain and wind caused difficulties, necessitating sheltering of the exposed electrics. In the gloom of early evening it became opportune to look again at the capture of the apex of the obelisk. Because of scaffold placement it was quite awkward to find good positions for the scanner, yet it was important to ensure that high quality scans were maintained.

The final number of scans was in excess of 400 , with each scan having up to 5 million points. When the data was processed it was found that specular reflections from the facets of the granite surface had left small holes in the point cloud which needed to be resolved. This was accomplished by an automated script where the local surface form was filled to repair missing data. The merged point cloud was also thinned, on the basis of contribution to form, to produce a 3D dataset that could be properly manipulated on a standard computer. The alignment for the obelisk was established using the geometric framework of the plinth, and the processed data exported complete with GOM Inspect, a free viewing package that allows users to view and manipulate the 3D scan data (Fig. 8).

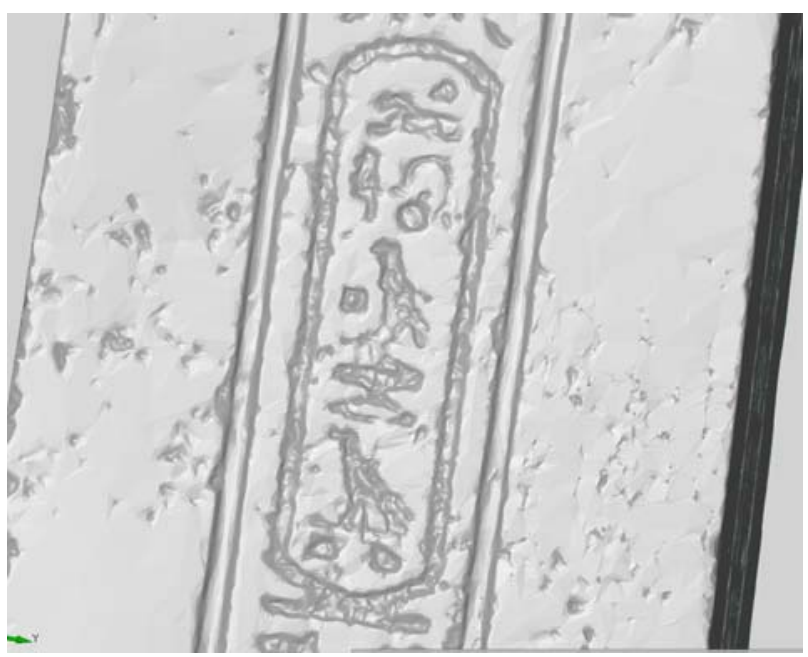

Figure 8: Rendering of the Cleopatra hieroglyph from the $3 D$ point cloud produced by the scanner.

The capture of this obelisk was quite different from the usual high-end metrology applications for which the ATOS equipment is designed. However, it proved to be well within the scanner capabilities to deliver a high quality dataset of a complex object in difficult conditions in a remarkably short time. This demonstrated that apparatus designed for the controlled environment of a factory or laboratory can also be used successfully in situ outdoors. 


\section{IMAGE PROCESSING}

Upon completion of the separate image and 3D data capture phases described in the previous two sections, we had for the shaft of the obelisk:

1) twelve sets of images and RTI files for the inscriptions on each of the four faces;

2) a merged point cloud for the complete surface, containing 4,811,689 points (geometry only).

The objective was to 'stitch together' the separate RTI files into a single RTI file to form a long vertical swathe for each face over the full height of the inscriptions on the shaft of the obelisk. The 3D point cloud provides a geometric framework with which to register each image, before merging. The procedure is shown schematically in Fig. 9.

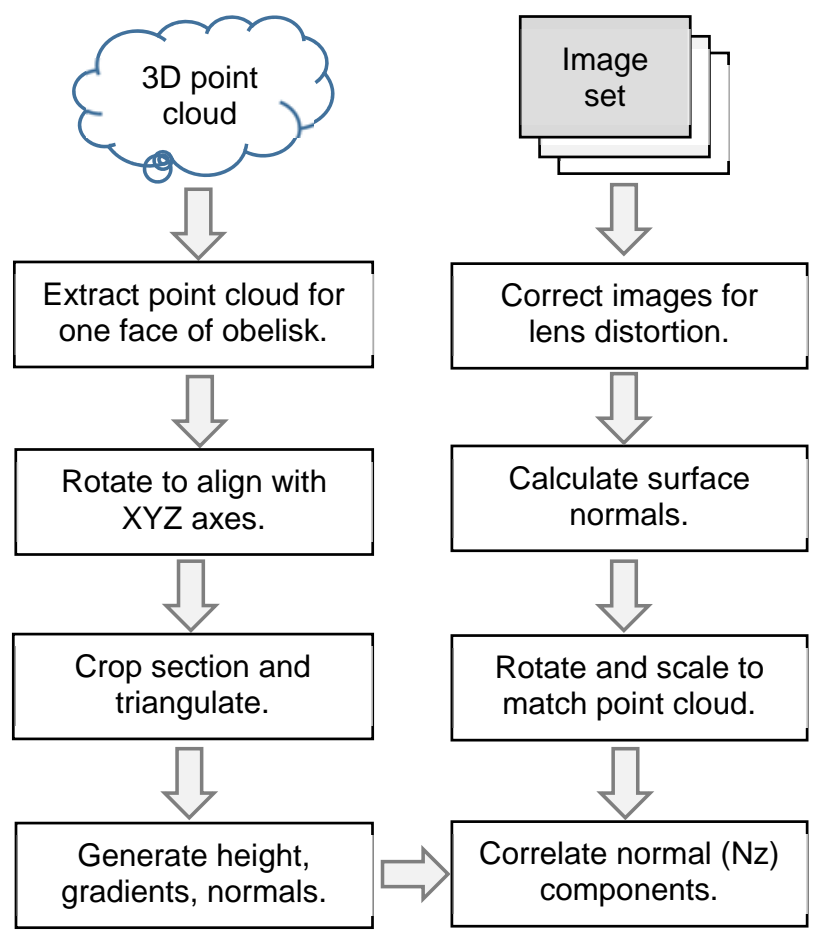

Figure 9: Processing steps for stitching images.

Partitioning the east face above the pedestal, there were $1,027,658$ points in the point cloud, with maximum width $(X)=663.7 \mathrm{~mm}$, height $(Y)=6169.9$ $\mathrm{mm}$, and depth $(Z)=15.9 \mathrm{~mm}$. The rotation of axes was performed by projecting the set of points onto the axes defined by the principal components.

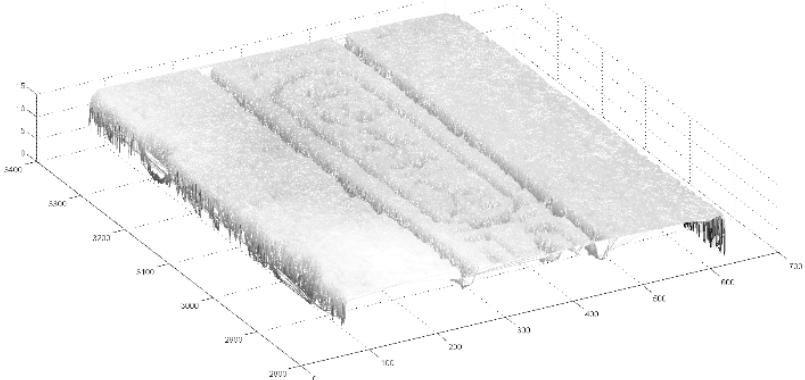

Figure 10: Triangulation of cropped section of point cloud, showing cartouche of Cleopatra on the east face.
A section was then cropped, corresponding to the coverage of the selected RTI image set, and the cropped point cloud was triangulated (Fig. 10). The height at each point was calculated on a grid of 5 pixels $/ \mathrm{mm}$ for the intersection of each row with the corresponding edges of the intersected triangles. This gave a digital terrain map (DTM) with a unique height at each pixel. The gradients could then be calculated as the differences along the $X$ and $Y$ axes (Fig. 11) and from these the normal vectors.

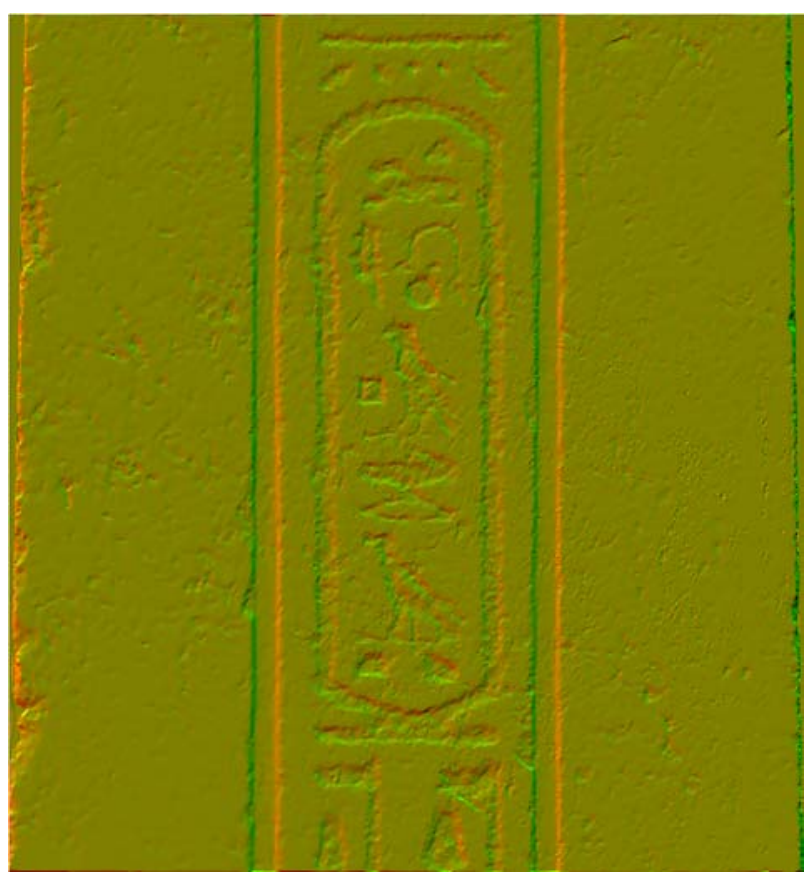

Figure 11: Gradient map from point cloud, visualised with $X$ gradients in red, and $Y$ gradients in green.

As with the lens of any camera, the Canon $50 \mathrm{~mm}$ lens causes geometric distortion in the images, which needs to be corrected before they can be compared with the orthographic geometry of the 3D scanner. The lens was characterised by taking a set of images of a photogrammetric target array at $\mathrm{UCL}$, from which the parameters of a lens distortion model could be estimated by the Vision Measurement System (VMS). The results show a pattern of distortion predominantly radially outwards (Fig. 12), with a maximum of 7.2 pixels.

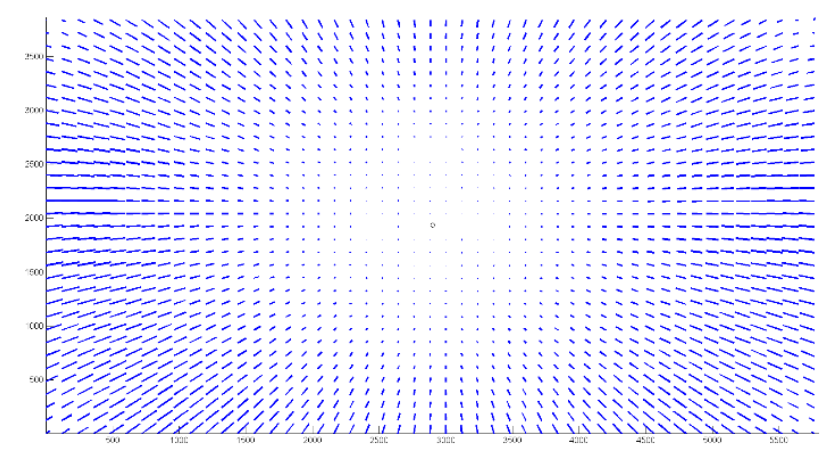

Figure 12: Image distortion map for Canon lens, with vectors from image location to true location at intervals of 120 pixels. Vectors are shown as 20x true length. 


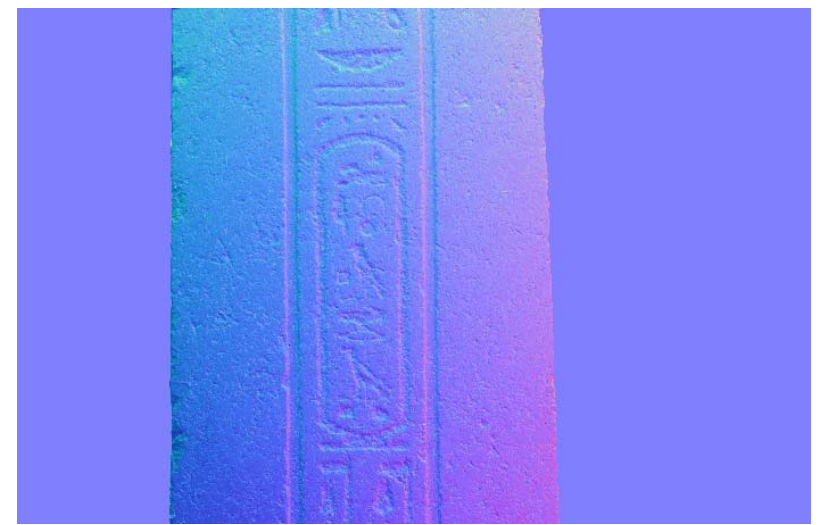

Figure 13: Normal vectors from photographic image set, corrected for convergence of rays through lens.

The surface normal vectors of the corrected images are computed by the bounded regression technique (MacDonald, 2014), and corrected for convergence of the rays from the surface through the perspective centre of the lens (Fig. 13). The $\mathrm{Z}$ component $(\mathrm{Nz})$ of the two sets of normals is extracted to match the image detail with the scanner detail, in order to establish the geometric correspondence at pixel level. Bordering the panel of hieroglyphics are two parallel channels cut into the granite to a depth of 4$5 \mathrm{~mm}, 14 \mathrm{~mm}$ in width and $200 \mathrm{~mm}$ apart (Fig. 14). By matching these features with a template in the form of a thick line segment, both their relative angle and scale can be determined, enabling photometric normals to be transformed to the same alignment and scale (5 pixels $/ \mathrm{mm})$ as the scanner normals.

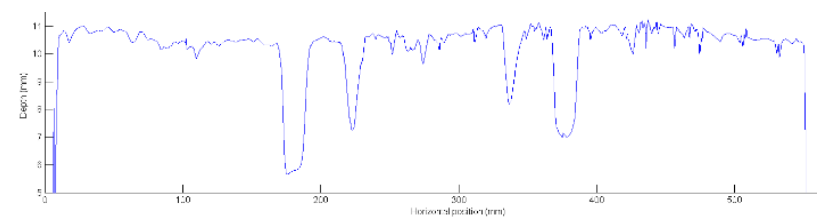

Figure 14: Horizontal section of surface of east face of obelisk, showing two channels and incisions.

Cross-correlation between the two sets of normals enables the camera normals to be translated into register with the scanner normals (Fig. 15). In an additional stage, cross-correlation may be performed at a local level, at each point on a grid, to implement a rubber-sheet transformation of the camera normals to ensure a fit to sub-pixel accuracy with the scanner normals.

\section{CONCLUSIONS}

The project has created a permanent image set and accurate dimensional surface record of the obelisk. These will be used in making new readings of the Greek and hieroglyphic inscriptions, even those now so worn that they are invisible to the naked eye. The image processing techniques described above will be used to stitch together all the RTI files for the overlapping individual sections into a single vertical swathe, enabling the entire face on each side to be viewed as a single entity in the RTI viewer, The photography and scanning of the pedestal will be done from ground level in a future phase.

\section{ACKNOWLEDGEMENTS}

We are indebted to The National Trust for facilitating the project and providing access to the monument at Kingston Lacy and erecting the scaffold platform. Thanks to Prof Stuart Robson (UCL) for assistance with the characterisation of camera lens distortion.

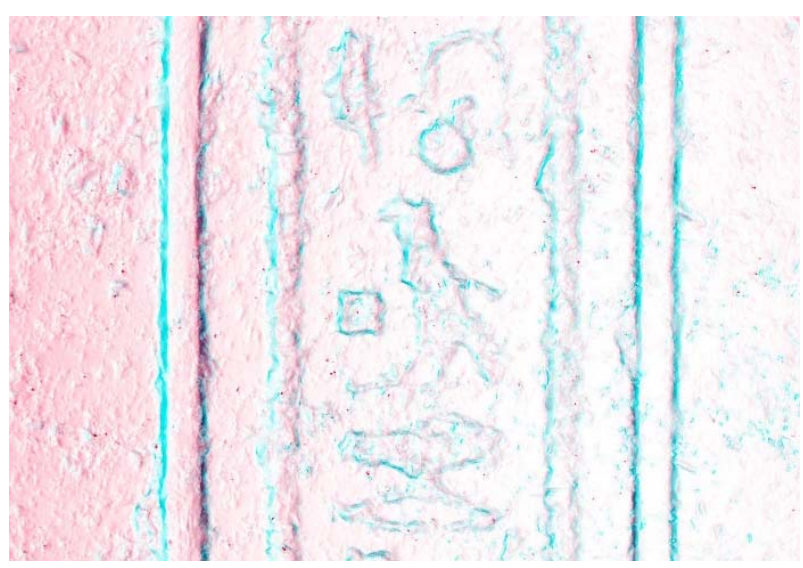

Figure 15: Detail of registered sets of normals, with scanner normals in red and photometric in cyan.

\section{REFERENCES}

Adkins, L. and R. (2001), The Keys of Egypt: The Obsession to Decipher Egyptian Hieroglyphs. HarperCollins, London.

Burstein, S.M. (1985), The Hellenistic Age from the Battle of Ipsos to the Death of Kleopatra VII. C.U.P., Cambridge.

Earl, G., Martinez, K. and Malzbender, T. (2010) Archaeological applications of polynomial texture mapping: analysis, conservation and representation, J. Archaeological Science, 37(8):2040-2050.

Edwards, I.E.S., (1980), Philae Resurrected, Unesco, Paris.

MacDonald, L.W. (2014) Colour and Directionality in Surface Reflectance, Proc. Conf. on Artificial Intelligence and the Simulation of Behaviour (AISB). MacQuitty, W. and J. (1976), Island of Isis: Philae, temple of the Nile. Macdonald and Jane's, London.

Parkinson, R. (1999), Cracking Codes: The Rosetta Stone and Decipherment. U. Calif. Press, London.

Salt, H. (1825), Essay on Dr. Young's and M. Champollion's Phonetic System of Hieroglyphs. London.

Vassilika, E. (1989), Ptolemaic Philae. Peeters, Leuven.

Wallis Budge, E.A. (1904), The decrees of Memphis and Canopus. Paul, Trench and Trübner, London. 